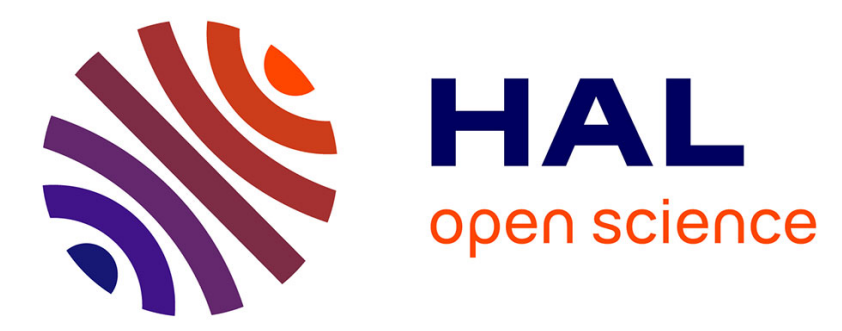

\title{
Characterization of \\ (Pt2 nm/Co0.4 nm)3/Ptx/IrMn7 nm multilayers by tomographic atom probe: On the role of a $\mathrm{Pt}$ spacer
}

\author{
A. Zarefy, R. Lardé, L. Lechevallier, F. Cuvilly, J. M. Le Breton, Vincent \\ Baltz, B. Rodmacq, B. Dieny
}

\section{To cite this version:}

A. Zarefy, R. Lardé, L. Lechevallier, F. Cuvilly, J. M. Le Breton, et al.. Characterization of $(\mathrm{Pt} 2 \mathrm{~nm} / \mathrm{Co} 0.4 \mathrm{~nm}) 3 / \mathrm{Ptx} / \mathrm{IrMn} 7 \mathrm{~nm}$ multilayers by tomographic atom probe: On the role of a $\mathrm{Pt}$ spacer. Journal of Applied Physics, 2009, 105, pp.103912. 10.1063/1.3125527 . hal-01683832

\section{HAL Id: hal-01683832 https://hal.science/hal-01683832}

Submitted on 25 May 2019

HAL is a multi-disciplinary open access archive for the deposit and dissemination of scientific research documents, whether they are published or not. The documents may come from teaching and research institutions in France or abroad, or from public or private research centers.
L'archive ouverte pluridisciplinaire HAL, est destinée au dépôt et à la diffusion de documents scientifiques de niveau recherche, publiés ou non, émanant des établissements d'enseignement et de recherche français ou étrangers, des laboratoires publics ou privés. 


\title{
Characterization of $\left(\mathrm{Pt}_{2} \mathrm{~nm} / \mathrm{Co}_{0.4 \mathrm{~nm}}\right)_{3} / \mathrm{Pt}_{x} / \mathrm{IrMn}_{7 \mathrm{~nm}}$ multilayers by tomographic atom probe: On the role of a $\mathrm{Pt}$ spacer
}

\author{
A. Zarefy, ${ }^{1}$ R. Lardé, ${ }^{1}$ L. Lechevallier, ${ }^{1, a)}$ F. Cuvilly, ${ }^{1}$ J. M. Le Breton, ${ }^{1}$ V. Baltz, ${ }^{2}$ \\ B. Rodmacq, ${ }^{2}$ and B. Dieny ${ }^{2}$ \\ ${ }^{1}$ Groupe de Physique des Matériaux, UMR CNRS 6634, Université de Rouen, Avenue de l'Université, \\ BP 12, 76801 Saint Etienne du Rouvray, France \\ ${ }^{2}$ INAC/SPINTEC (URA 2512 CNRS/CEA), CEA/Grenoble, 17Avenue des Martyrs, 38054 Grenoble Cedex 9 , \\ France
}

(Received 24 November 2008; accepted 2 April 2009; published online 27 May 2009)

\begin{abstract}
Structural investigation of $\mathrm{Ta}_{3} \mathrm{~nm} /\left[\left(\mathrm{Pt}_{2} \mathrm{~nm} / \mathrm{Co}_{0.4 \mathrm{~nm}}\right)_{3} / \mathrm{Pt}_{x} / \mathrm{IrMn}_{7 \mathrm{~nm}}\right]_{7} / \mathrm{Pt}_{10 \mathrm{~nm}}$ multilayers without $(x=0 \mathrm{~nm})$ and with $(x=0.4 \mathrm{~nm})$ a Pt spacer has been performed by laser-assisted tomographic atom probe. Without a Pt spacer a strong intermixing is observed at the Co/IrMn interface. In the multilayer containing a Pt spacer the $\mathrm{Co} / \mathrm{Pt} / \mathrm{IrMn}$ interface is very weakly intermixed. It thus appears that the Pt spacer acts as a diffusion barrier that prevents the Ir and Mn atoms from diffusing into the Co layer. The consequences of this effect on the magnetic properties are discussed. The exchange bias field and the anisotropy direction of these two multilayers are analyzed and correlated with the structural investigation. (c) 2009 American Institute of Physics. [DOI: 10.1063/1.3125527]
\end{abstract}

When a ferromagnetic (FM) layer in contact with an antiferromagnetic (AFM) layer is field cooled from above the blocking temperature of the AFM layer, the magnetic interactions at the AFM/FM interface lead to a shift of the hysteresis loop (exchange bias field) and to an enhancement of the coercivity of the FM layer. ${ }^{1-3}$ During the past decade, this effect has been extensively studied due to its applications in the development of spin electronic devices. ${ }^{4,5}$ First discovered in FM/AFM layers exhibiting an in-plane magnetic anisotropy, it has also been observed few years ago in multilayers with an out-of-plane magnetic anisotropy ${ }^{6,7}$ offering the possibility to develop spin valves or tunnel junctions with perpendicular-to-plane magnetization. ${ }^{8,9}$ Among these different systems, $\mathrm{FM}(\mathrm{Pt} / \mathrm{Co})_{n}$ (where $n$ is the number of repeats) multilayers exchange coupled to AFM IrMn layers exhibit a perpendicular exchange bias at room temperature. ${ }^{10-12}$

Recently, it has been shown that the introduction of a Pt spacer between the last Co layer of the $(\mathrm{Pt} / \mathrm{Co})_{n} \mathrm{FM}$ multilayer and the (FeMn or IrMn) AFM layer strongly increases the exchange bias field $H_{E}{ }^{9-11}$

This phenomenon being linked to an increase of the perpendicular magnetic anisotropy, it could be deduced that the Pt spacer reinforces the perpendicular direction of the spins located at the FM/AFM interface. ${ }^{10}$ It is known that the exchange bias effect due to the exchange coupling at the FM/ AFM interface is strongly influenced by the interface roughness and the chemical intermixing at this interface. ${ }^{2}$ However, no direct analysis of the chemical intermixing at the FM/AFM interface has been reported in literature.

In this paper, we report on the influence of a Pt spacer at the FM/AFM interface on the chemical and structural properties in $\left[\left(\mathrm{Pt}_{2 \mathrm{~nm}} / \mathrm{Co}_{0.4 \mathrm{~nm}}\right)_{3} / \mathrm{Pt}_{x} / \mathrm{IrMn}_{7 \mathrm{~nm}}\right]_{7}$ multilayers. We correlate these properties with the exchange bias properties.

${ }^{a)}$ Electronic mail: luc.lechevallier@univ-rouen.fr.
In such multilayers, the very small thickness of the layers makes the structural characterization of interfaces extremely difficult. To investigate this system at the atomic scale, the laser-assisted tomographic atom probe (LATAP) has been used. This technique offers an ultrahigh spatial resolution (depth resolution $\sim 0.1 \mathrm{~nm}$ ) and provides a powerful method to observe the interface chemistry at the atomic scale $^{13}$ as this has already been used to characterize magnetoresistive ${ }^{14,15}$ and magnetostrictive ${ }^{16}$ multilayers. The principle is based on field evaporation of surface atoms from a sample prepared in a tip shape with a top radius less than $50 \mathrm{~nm}$.

The two multilayers were deposited at room temperature by dc magnetron sputtering, using a $5.3 \times 10^{-6}$ Pa base pressure and a $0.25 \mathrm{~Pa}$ Ar pressure during deposition. They were then annealed to $550 \mathrm{~K}$ and cooled from $550 \mathrm{~K}$ under a -2.4 kOe magnetic field applied in the direction perpendicular to the film plane. They were deposited on a prepatterned substrate consisting of an assembly of flattopped $\mathrm{Si}(100)$ posts. The silicon posts have a height of $100 \mu \mathrm{m}$ and an area of $10 \times 10 \mu \mathrm{m}^{2}$. After deposition, the posts were picked off from the wafer, glued at the top of a thin rod with conductive epoxy glue and tip shaped using a focused Ga ion beam (30 $\mathrm{kV}) .{ }^{14,15}$ To reduce Ga implantation and damages in the region of interest, the multilayers were capped with $500 \mathrm{~nm}$ of $\mathrm{Cr}$ and the final step of the milling of the tip was performed at low acceleration voltage $(2 \mathrm{kV})$. Moreover, according to the very small thicknesses of the layers, the $(\mathrm{Pt} / \mathrm{Co})_{3} / \mathrm{IrMn}$ sequence has been repeated seven times in order to obtain a multilayer thick enough to allow an accurate analysis of the interfaces in regions nonperturbed by the damages created by the $\mathrm{Ga}$ ion beam. Prepared tips were then analyzed by LATAP at $80 \mathrm{~K}$ in an ultrahigh vacuum chamber at a $10^{-8} \mathrm{~Pa}$ pressure.

The principle of atom probe is based on the field evaporation of surface atoms as ions and their identification by time of-flight mass spectrometry. The high electric field re- 
quired (a few tens of $\mathrm{V} / \mathrm{nm}$ ) is obtained by applying a high voltage to the specimen prepared in the form of a sharply pointed needle (tip radius less than $50 \mathrm{~nm}$ ). The tip is biased at a high positive dc voltage $V_{o}$ in the $2-10 \mathrm{kV}$ range and cooled to low temperatures $(20-80 \mathrm{~K})$. The vacuum in the analysis chamber is usually in the $10^{-8} \mathrm{~Pa}$ range. Surface atoms are then field evaporated by means of high-frequency $(100 \mathrm{kHz})$ laser pulses superimposed on the dc voltage $V_{o} .{ }^{17}$ The femtosecond laser pulsed system used is an amplified ytterbium-doped laser (AMPLITUDE SYSTEM $s$-pulse) with a pulse length of $350 \mathrm{fs}$. The evaporated atoms are collected by a time-resolved position detector located in front of the specimen. It allows to measure the time of flight of each ion and to record its impact position. Both information allow to deduce the chemical nature of evaporated ions and to calculate the position from which atoms originate at the tip surface. The lateral positions of atoms at the surface of the tip sample are obtained from a reverse projection of ion impacts coordinates on the position sensitive detector. The depth position is deduced from the order of detection of atoms. ${ }^{18}$ The sample is field-evaporated atomic layer per atomic layer, and a $10^{4} \mathrm{~nm}^{3}$ typical volume of analysis is collected in a few hours. After the three-dimensional (3D) reconstruction of the analyzed volume, the spatial distribution of atoms is observable at the atomic scale in the real space. From the data set of the 3D reconstruction, chemical composition or concentration depth profiles can be calculated everywhere in the analyzed volume. The depth resolution is measured to values better than half an atomic plane. ${ }^{19}$

The magnetic properties of the two multilayers deposited onto Si plane substrates were investigated using a Quantum Design (MPMS XL 5T) superconducting quantum interference device (SQUID) magnetometer. Hysteresis loops were obtained at room temperature with the magnetic field applied perpendicular to the film direction.

Figure 1 shows the $3 \mathrm{D}$ reconstructions of the analyzed volumes representing one $(\mathrm{Pt} / \mathrm{Co}) / \mathrm{Pt}_{x} / \mathrm{IrMn}$ sequence of the two multilayers. These reconstructed volumes were oriented in order to image the interfaces in cross section i.e., perpendicular to the plane of view. In the two specimens the three Co layers are clearly observable. In the spacer free specimen (SF specimen) [Fig. 1(a)], the Co layer at the Co/IrMn interface (third Co layer, i.e., $\mathrm{Co}_{(3)}$ ) is strongly intermixed with the IrMn layer. In contrast, for the Pt spacer containing specimen (SC specimen) [Fig. 1(b)], the $\mathrm{Co}_{(3)}$ layer is well separated from the IrMn layer. The Co/IrMn interface in the SF specimen appears to be strongly intermixed whereas the $\mathrm{Co} /$ $\mathrm{Pt} / \mathrm{IrMn}$ interface in the SC specimen is very weakly intermixed.

The concentration profiles of the $\mathrm{Pt}, \mathrm{Co}$, and $\mathrm{Mn}$ atoms corresponding to one sequence of each specimen are shown in Fig. 2. For the sake of clarity, the Ir profiles that are connected to the Mn ones are not represented. Figures 2(b) and 2(d) are enlargements of Figs. 2(a) and 2(c) in the region close to the FM/AFM interface.

For the two specimens, the concentration profiles of Co and $\mathrm{Pt}$ within the $(\mathrm{Pt} / \mathrm{Co})_{3} \mathrm{FM}$ multilayer are similar, showing that the $\mathrm{Co}_{(1)}$ and $\mathrm{Co}_{(2)}$ layers (deposited on the first and second Pt layers) are intermixed with Pt, in agreement with

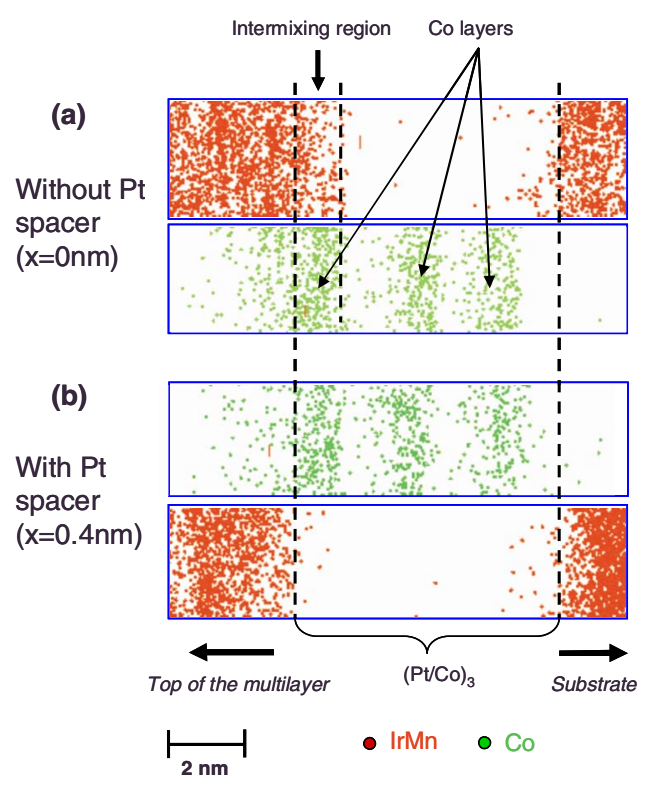

FIG. 1. (Color online) Two-dimensional (2D) projection of the analyzed volumes representing one sequence of the $\left[\left(\mathrm{Pt}_{2} \mathrm{~nm} / \mathrm{Co}_{0.4} \mathrm{~nm}\right)_{3} /\right.$ $\left.\mathrm{Pt}_{x} / \mathrm{IrMn}_{7}{ }_{\mathrm{nm}}\right]_{7}$ multilayers. (a) Without Pt spacer $(x=0 \mathrm{~nm})$ and (b) with $\mathrm{Pt}$ spacer $(x=0.4 \mathrm{~nm})$.

what was suggested by Nakajima et al. ${ }^{20}$ In contrast, the concentration profile of the $\mathrm{Co}_{(3)}$ layer is very different for the two specimens. For the SF specimen [Fig. 2(a)], the $\mathrm{Co}_{(3)}$ layer is very diffuse and broader than the $\mathrm{Co}_{(1)}$ and $\mathrm{Co}_{(2)}$ layers. The Co atoms are strongly intermixed with $\mathrm{Mn}$ and $\mathrm{Pt}$ atoms in the whole width of the layer. The Mn-Pt-Co intermixing is clearly observed in Fig. 2(b). Indeed, the Mn atoms are present in the whole thickness of the $\mathrm{Co}_{(3)}$ layer, the $\mathrm{Mn}$ concentration becoming negligible when the Pt concentration strongly increases.

For the SC specimen [Fig. 2(c)], the $\mathrm{Co}_{(3)}$ layer has approximately the same shape and dimension as the $\mathrm{Co}_{(1)}$ and $\mathrm{Co}_{(2)}$ layers. The Co atoms are slightly intermixed with $\mathrm{Mn}$ and Pt. One can observe in Fig. 2(d) a small peak corresponding to the $0.4 \mathrm{~nm}$ Pt spacer. It clearly appears that the Mn concentration strongly decreases when the Pt concentration increases. This is due to the presence of the Pt spacer. The Mn concentration being almost negligible in the whole thickness of the $\mathrm{Co}_{(3)}$ layer, the Pt spacer appears to prevent the diffusion of the Mn atoms in this layer during the deposition process. The Pt spacer thus acts as a diffusion barrier for the migration of $\mathrm{Mn}$ toward the $\mathrm{Co}_{(3)}$ layer. In other words, Mn (but also Ir which presents the same profile near the Pt spacer) is thought to diffuse much slower in Pt than in Co. In the SF specimen, a strong intermixing between Ir, Mn, and Co atoms occurs during IrMn layer deposition on the $\mathrm{Co}_{(3)}$ layer. Ir and $\mathrm{Mn}$ atoms diffuse through the whole thickness of the $\mathrm{Co}_{(3)}$ layer down to the $\mathrm{Pt}_{(3)}$ layer where they are stopped. In the two specimens the $\mathrm{Pt}$ spacer and the $\mathrm{Pt}_{(3)}$ layer (for the SF specimen) act as a diffusion barrier.

In multilayers, both the chemical nature and the roughness of the interfaces, in relation with the possible atomic intermixing, determine the magnetic properties, such as the exchange bias effect. For example, in the $\mathrm{Mn}_{x} \mathrm{Pt}_{1-x} /$ Co sys- 

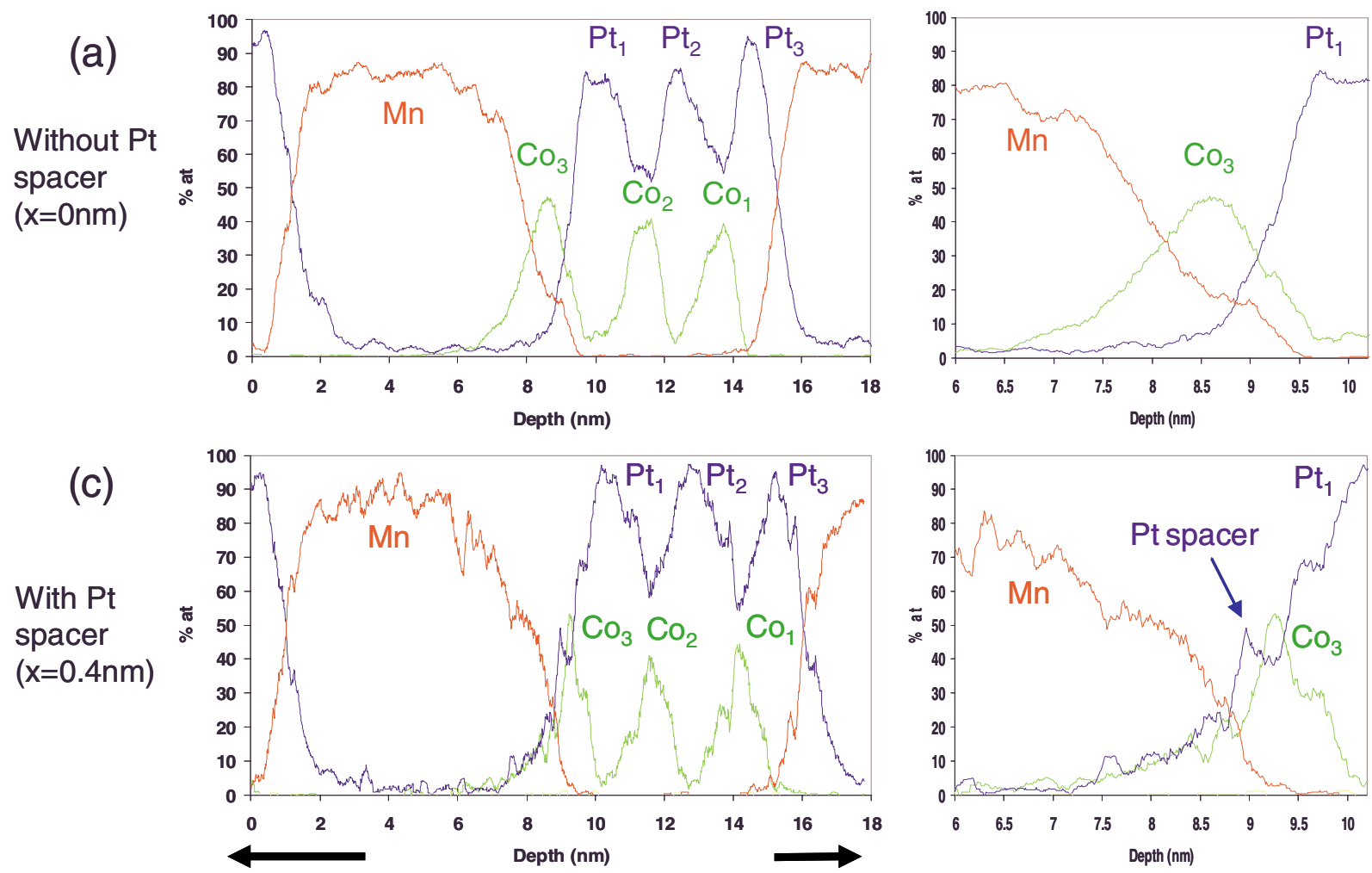

(d)

Top of the multilayer

Substrate

FIG. 2. (Color online) Concentration profiles of the $\mathrm{Pt}, \mathrm{Co}$, and $\mathrm{Mn}$ atoms corresponding to the 2D projection of one sequence of the $\left[\left(\mathrm{Pt}_{2 \mathrm{~nm}} / \mathrm{Co}_{0.4 \mathrm{~nm}}\right)_{3} / \mathrm{Pt}_{x} / \mathrm{IrMn}_{7 \mathrm{~nm}}\right]$ multilayers: [(a) and (b)] without Pt spacer $(x=0 \mathrm{~nm})$ and [(c) and (d)] with Pt spacer $(x=0.4 \mathrm{~nm})$. (b) and (d) are the enlargements of profiles close to the FM/AFM interface.

tem, interdiffusion lowers $H_{E}{ }^{21}$ These structural parameters are closely related to the growth mechanisms involved during the deposition of the different layers. ${ }^{14,22,23}$ During deposition, ballistic phenomena occur and can lead to the penetration of incident atoms into the layers and to the ejection of surface atoms. This phenomenon, which increases with the impact energy and varies according to the chemical nature of the atoms, is responsible for the occurrence of asymmetric interfaces in $\mathrm{CoFe} / \mathrm{Cu} / \mathrm{CoFe}$ trilayers. ${ }^{14,23}$ For the two specimens investigated here, the fact that the Pt atomic weight is much larger than the Co one very likely limits the impactinduced interdiffusion mechanism for the specimen containing a Pt spacer and thus the intermixing between the Ir, Mn, $\mathrm{Pt}$, and Co atoms. In this case, the Pt spacer acts as a ballistic diffusion barrier.

Moreover, as the Co melting point is lower than the Pt one, the diffusion of Ir and $\mathrm{Mn}$ incident atoms is probably more pronounced in a Co layer than in a Pt layer. Accordingly, for the SF specimen, the high diffusion between the different atoms at the Co/IrMn interface should be induced also by a thermal process. In such a case, the Pt spacer also acts as a thermal diffusion barrier.

The two specimens present $\mathrm{Co}_{0.4 \mathrm{~nm}} / \mathrm{Pt}_{\mathrm{x}} / \mathrm{IrMn}_{7 \mathrm{~nm}}$ and $\mathrm{IrMn}_{7 \mathrm{~nm}} / \mathrm{Pt}_{2} \mathrm{~nm} / \mathrm{Co}_{0.4 \mathrm{~nm}}$ interfaces. The thickness of the $\mathrm{Pt}$ layer $(2 \mathrm{~nm})$ being very large for the $\mathrm{IrMn}_{7 \mathrm{~nm}} / \mathrm{Pt}_{2} \mathrm{~nm} / \mathrm{Co}_{0.4 \mathrm{~nm}}$ interface, we can consider that the exchange bias interaction is only due to the magnetic moments located at the $\mathrm{Co}_{0.4 \mathrm{~nm}} / \mathrm{Pt}_{\mathrm{x}} / \mathrm{IrMn}_{7 \mathrm{~nm}}$ interface ( $\mathrm{x}$ $<0.4 \mathrm{~nm}){ }^{9}$
The hysteresis loops of the two specimens are shown in Fig. 3. The exchange bias fields $H_{E}$ are 12 and 90 Oe for the SF and SC specimens, respectively. The increase in $H_{E}$ for the SC specimen compared to the SF specimen has already been ascribed to the improvement of the out-of-plane orientation of the $\mathrm{Co}_{(3)}$ layer magnetization within the multilayer due to the addition of a Co-Pt interface and thus to an additional interfacial out-of-plane anisotropy energy. ${ }^{9}$ However this cannot explain the order of magnitude of increase in $H_{E}$. ${ }^{9}$ The data deduced from tomographic atom probe experiments (Figs. 1 and 2) indicate that the Pt spacer also proves to be an efficient diffusion barrier against the interdiffusion of Ir, Mn, and Co atoms at the FM/AFM interface, thus mostly contributing to the extra out-of-plane anisotropy of the $\mathrm{Co}_{(3)}$ layer of the $\left(\mathrm{Pt}_{2} \mathrm{~nm} / \mathrm{Co}_{0.4 \mathrm{~nm}}\right)_{3}$ multilayer.

We observe that these two specimens do not display square hysteresis loops but show nucleation in positive field, in contrast to the case of one repeat of the sequence where the loops exhibits a square shape. ${ }^{9}$ Moreover the SC specimen [Fig. 3(b)] surprisingly shows a more tilted hysteresis loop than SF specimen [Fig. 3(a)]. In multilayers the magnetization reversal of a magnetic layer strongly depends on its thickness. ${ }^{24,25}$ Gehanno et al. ${ }^{25}$ showed that above a critical film thickness, the single domain magnetic configuration no more prevails over the multidomain one. Our present samples are composed of seven $\left(\mathrm{Pt}_{2} \mathrm{~nm} / \mathrm{Co}_{0.4 \mathrm{~nm}}\right)_{3}$ multilayers separated by $\mathrm{Pt}_{\mathrm{x}} / \mathrm{IrMn}_{7 \mathrm{~nm}}$ bilayers. The $\left(\mathrm{Pt}_{2} \mathrm{~nm} / \mathrm{Co}_{0.4} \mathrm{~nm}\right)_{3}$ multilayers, repeated seven times in the 

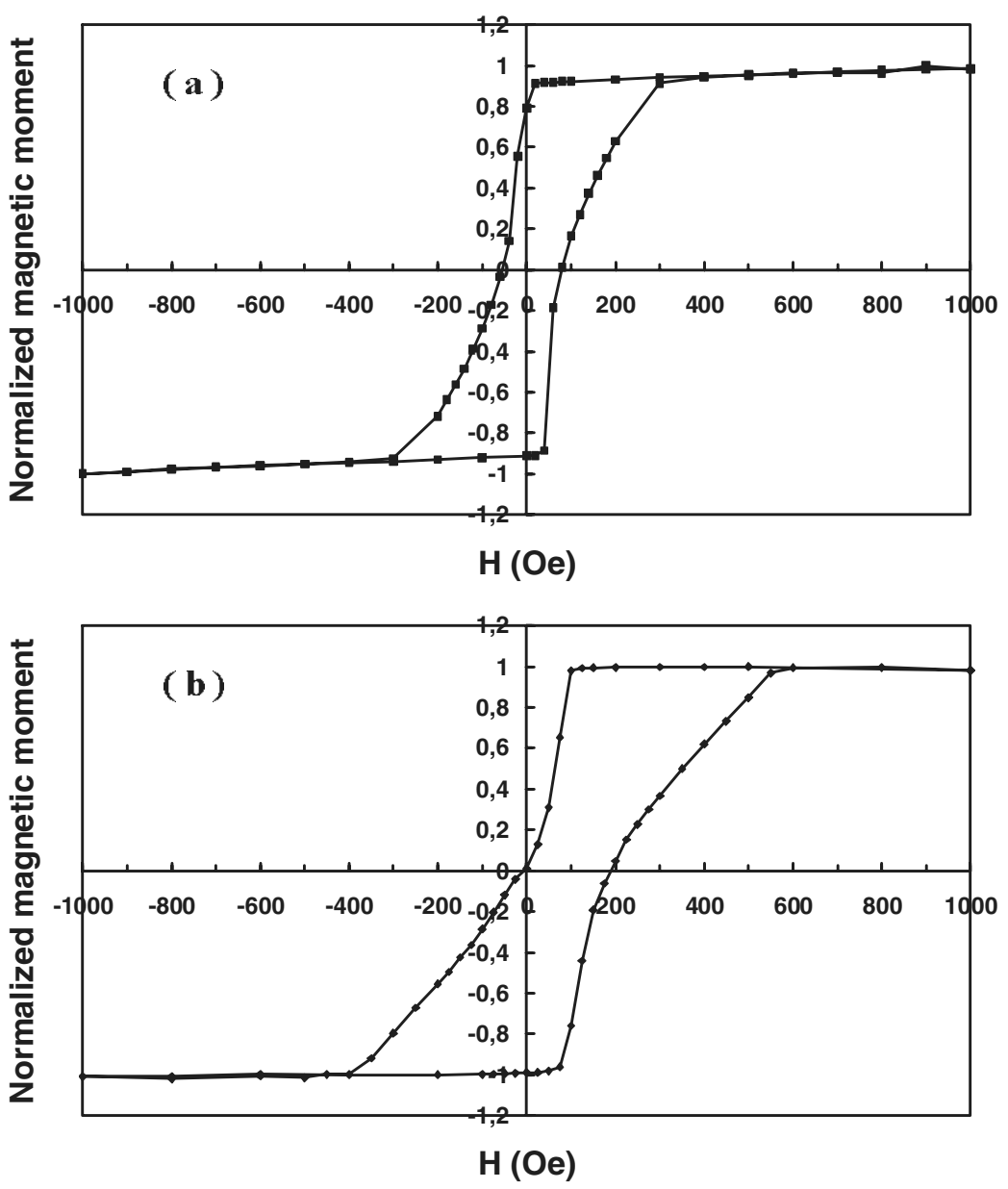

FIG. 3. Hysteresis loops of the $\mathrm{Ta}_{3} \mathrm{~nm} /$ $\left[\left(\mathrm{Pt}_{2 \mathrm{~nm}} / \mathrm{Co}_{0.4 \mathrm{~nm}}\right)_{3} / \mathrm{Pt}_{x} / \mathrm{IrMn}_{7 \mathrm{~nm}}\right]_{7} / \mathrm{Pt}_{10 \mathrm{~nm}}$ specimens measured at room temperature by SQUID magnetometry after cooling from $550 \mathrm{~K}$ under a $-2.4 \mathrm{kOe}$ magnetic field applied in the direction perpendicular to the film plane: (a) for $x=0 \mathrm{~nm}$ (SF specimen) and (b) for $x=0.4 \mathrm{~nm}$ (SC specimen). whole specimen are very likely magnetically coupled via magnetostatic energy terms, which favor a multidomain configuration, in contrast to the single domain configuration of a sole $\left(\mathrm{Pt}_{2} \mathrm{~nm} / \mathrm{Co}_{0.4 \mathrm{~nm}}\right)_{3}$ multilayer. ${ }^{26}$ Due to these magnetostatic interactions, the system behaves like a monolayer with increased magnetic effective thickness. ${ }^{26}$ Similarly our seven $\left(\mathrm{Pt}_{2} \mathrm{~nm} / \mathrm{Co}_{0.4 \mathrm{~nm}}\right)_{3}$ multilayers are magnetostatically coupled via the $\mathrm{Pt}_{\mathrm{x}} / \mathrm{IrMn}_{7} \mathrm{~nm}$ bilayers which also tend to favor the formation of a multidomain magnetic configuration. The whole stack also behaves like a sample with an enhanced magnetic effective thickness leading to rather tilted loops for the two specimens.

For $\mathrm{x}=0.4 \mathrm{~nm}$, the out-of-plane orientation of the topmost $\mathrm{Co}_{(3)}$ layers of the $\left(\mathrm{Pt}_{2 \mathrm{~nm}} / \mathrm{Co}_{0.4 \mathrm{~nm}}\right)_{3}$ multilayers is improved with respect to the case of $x=0 \mathrm{~nm}$. It thus results that the out-of-plane magnetic stray fields which appear when the system breaks into domains are larger for $x$ $=0.4 \mathrm{~nm}$ than for $x=0 \mathrm{~nm}$. The SC specimen thus exhibits larger intermultilayer magnetostatic interactions, which lead to the observation of a more tilted loop with respect to the SF specimen. In the SC specimen, the stray fields by the seven $\left(\mathrm{Pt}_{2} \mathrm{~nm} / \mathrm{Co}_{0.4 \mathrm{~nm}}\right)_{3}$ multilayers lead to a stronger magnetostatic coupling which favors a multidomain configuration of the whole sample. In contrast, for the SF specimen, due to the tilted orientations of the $\mathrm{Co}_{(3)}$ layer spins, the stray fields by the $\left(\mathrm{Pt}_{2} \mathrm{~nm} / \mathrm{Co}_{0.4 \mathrm{~nm}}\right)_{3}$ multilayers are lower than for the previous specimen, leading to a weaker magnetostatic coupling. The hysteresis loop obtained for the SF specimen is thus squarer than the hysteresis loop of the SC specimen.

To conclude, the LATAP investigation of the two $\mathrm{Ta}_{3 \mathrm{~nm}} /\left[\left(\mathrm{Pt}_{2 \mathrm{~nm}} / \mathrm{Co}_{0.4 \mathrm{~nm}}\right)_{3} / \mathrm{Pt}_{x} / \mathrm{IrMn}_{7 \mathrm{~nm}}\right]_{7} / \mathrm{Pt}_{10 \mathrm{~nm}}$ multilayers with $x=0 \mathrm{~nm}$ and $x=0.4 \mathrm{~nm}$ allowed to compare and accurately characterize the chemistry of these FM/AFM interfaces. The positive influence of a Pt spacer is related to the limited $\mathrm{Co} / \mathrm{MnIr}$ interdiffusion at the FM/AFM interface, allowing to obtain a chemical structure leading to both the reinforcement of the perpendicular magnetic anisotropy and the increase of the exchange bias field.

The authors would like to thank F. Vurpillot, E. Cadel, A. Bostel, and D. Blavette for numerous and useful discussions.

${ }^{1}$ W. H. Meiklejohn and C. P. Bean, Phys. Rev. 102, 1413 (1956).

${ }^{2}$ J. Nogués and I. K. Schuller, J. Magn. Magn. Mater. 192, 203 (1999).

${ }^{3}$ B. Dieny, V. S. Speriosu, S. S. P. Parkin, B. A. Gurney, D. R. Wilhoit, and D. Mauri, Phys. Rev. B 43, 1297 (1991).

${ }^{4}$ S. Tehrani, J. M. Slaughter, M. Deherrera, B. N. Engel, N. D. Rizzo, J. Slater, M. Durlam, R. W. Dave, J. Janesky, B. Butcher, K. Smith, and G. Grynkewich, Proc. IEEE 91, 703 (2003).

${ }^{5}$ S. Maat, K. Takano, S. S. P. Parkin, and E. E. Fullerton, Phys. Rev. Lett. 87, 087202 (2001).

${ }^{6}$ J. Sort, B. Dieny, M. Fraune, C. Koenig, F. Lunnebach, B. Beschoten, and G. Güntherodt, Appl. Phys. Lett. 84, 3696 (2004).

${ }^{7}$ C. H. Marrows, Phys. Rev. B 68, 012405 (2003).

${ }^{8}$ F. Garcia, J. Sort, B. Rodmacq, S. Auffret, and B. Dieny, Appl. Phys. Lett. 83, 3537 (2003).

${ }^{9}$ J. Sort, V. Baltz, F. Garcia, B. Rodmacq, and B. Dieny, Phys. Rev. B 71, 054411 (2005).

${ }^{10}$ S. van Dijken, J. Moritz, and J. M. D. Coey, J. Appl. Phys. 97, 063907 
(2005).

${ }^{11}$ J. Sort, F. Garcia, B. Rodmacq, S. Auffret, and B. Dieny, J. Magn. Magn Mater. 272-276, 355 (2004)

${ }^{12}$ R. F. Jiang and C. H. Lai, J. Magn. Magn. Mater. 272-276, 2312 (2004).

${ }^{13}$ D. Blavette, B. Deconihout, A. Bostel, J.-M. Sarrau, M. Bouet, and A. Menand, Rev. Sci. Instrum. 64, 2911 (1993).

${ }^{14}$ X. W. Zhou, H. N. G. Wadley, R. A. Johnson, D. J. Larson, N. Tabat, A. Cerezo, A. K. Petford-Long, G. D. W. Smith, P. H. Clifton, R. L. Martens, and T. F. Kelly, Acta Mater. 49, 4005 (2001).

${ }^{15}$ D. J. Larson, A. K. Petford-Long, Y. Q. Ma, and A. Cerezo, Acta Mater. 52, 2847 (2004).

${ }^{16}$ A. Grenier, R. Lardé, E. Cadel, F. Vurpillot, J. Juraszek, J. Teillet, and N. Tiercelin, J. Appl. Phys. 102, 033912 (2007).

${ }^{17}$ B. Gault, F. Vurpillot, A. Vella, M. Gilbert, A. Menand, D. Blavette, and B. Deconihout, Rev. Sci. Instrum. 77, 043705 (2006).

${ }^{18}$ P. Bas, A. Bostel, B. Deconihout, and D. Blavette, Appl. Surf. Sci. 87-88,
298 (1995).

${ }^{19}$ R. Lardé, L. Lechevallier, A. Zarefy, A. Bostel, J Juraszek, J.-M. Le Breton, B. Rodmacq, and B. Dieny, J. Appl. Phys. 105, 084307 (2009).

${ }^{20}$ N. Nakajima, T. Koide, T. Shidara, H. Miyauchi, H. Fukutani, A. Fujimori, K. Iio, T. Katayama, M. Nyvlt, and Y. Suzuki, Phys. Rev. Lett. 81, 5229 (1998).

${ }^{21}$ E. H. Morales, Y. Wang, D. Lederman, A. J. Kellock, and M. J. Carey, J. Appl. Phys. 93, 4729 (2003).

${ }^{22}$ J. C. S. Kools, J. Appl. Phys. 77, 2993 (1995).

${ }^{23}$ X. W. Zhou and H. N. G. Wadley, J. Appl. Phys. 84, 2301 (1998).

${ }^{24}$ S. Hashimoto, Y. Ochiai, and K. Aso, J. Appl. Phys. 67, 4429 (1990).

${ }^{25}$ V. Gehanno, Y. Samson, A. Marty, B. Gilles, and A. Chamberod, J. Magn. Magn. Mater. 172, 26 (1997).

${ }^{26}$ V. Baltz, A. Marty, B. Rodmacq, and B. Dieny, Phys. Rev. B 75, 014406 (2007). 